\begin{tabular}{|c|l|}
\hline Title & $\begin{array}{l}\text { Distinctive features of the skull of the Ryukyu Scops OwI from Minami-daito Island, reveal ed by computed tomography } \\
\text { scanning }\end{array}$ \\
\hline Author(s) & Sawada, A kira; Y amasaki, Takeshi; I wami, Y asuko; Takagi, Masaoki \\
\hline Citation & $\begin{array}{l}\text { Ornithological science, 17(1), 45-54 } \\
\text { https://doi.org/40.2326/0sj.17.45 }\end{array}$ \\
\hline Issue Date & 2018-01 \\
\hline Doc URL & http://hdl.handle.net/2115/76443 \\
\hline Type & article \\
\hline File Information & Ornithol Sci 17 45-54.pdf \\
\hline
\end{tabular}

Instructions for use 


\title{
Distinctive features of the skull of the Ryukyu Scops Owl from Minami-daito Island, revealed by computed tomography scanning
}

\author{
Akira SAWADA ${ }^{1}$, Takeshi YAMASAKI ${ }^{2}$, Yasuko IWAMI ${ }^{2}$ and Masaoki TAKAGI ${ }^{3, \#}$ \\ ${ }^{1}$ Department of Biology and Geosciences, Graduate School of Science, Osaka City University, 3-3-138 \\ Sugimoto, Sumiyoshi, Osaka 558-8585, Japan \\ ${ }^{2}$ Laboratory of Natural History, Yamashina Institute for Ornithology, 115 Konoyama, Abiko, Chiba 270-1145, \\ Japan \\ ${ }^{3}$ Department of Natural History Science, Graduate School of Science, Hokkaido University, Kita 10, Nishi 8, \\ Kita-ku, Sapporo 060-0810, Japan
}

\section{ORNITHOLOGICAL SCIENCE \\ (C) The Ornithological Society of Japan 2018}

\begin{abstract}
Morphological differentiation of island-dwelling organisms provides model systems for studying evolution. Computed tomography (CT) scanning is an entirely non-destructive technique that provides detailed three-dimensional (3D) images of physical structures. Geometric morphometrics has been increasingly used in avian morphology studies by analyzing 3D data obtained from CT scans. We used geometric morphometrics to evaluate the morphological details of the skulls of three, genetically distinct, island populations of the Ryukyu Scops Owl Otus elegans: O. e. elegans from the northern part of the Ryukyu Archipelago, O. e. elegans from the southern part of the Ryukyu Archipelago, and O. e. interpositus from Minami-daito Island. Skulls were scanned using an X-ray CT system and the digitized 3D coordinates of 16 landmarks for each skull were analyzed in order to describe geometric morphometric features. O. e. interpositus was found to have a significantly smaller skull than either population of $O$. e. elegans. From principle component analysis of shape variation, we also found that the skull shape of $O$. e. interpositus differed significantly from both the northern and southern groups of $O$. e. elegans. This difference was in terms of PC1, which mainly represented relative anteroposterior length, and angle of the orbit. We inferred that the small skull of O. e. interpositus is partly a consequence of the particular founders of the population, or evolutionary selection that has taken place on Minami-daito Island and that the distinctive shape of the skull of $O$. e. interpositus is partly a consequence of adaptations for foraging efficiency, or of morphological integration.
\end{abstract}

Key words CT scan, Geometric morphometrics, island, Otus elegans, skull
Morphological features of organisms can reflect their evolutionary histories. In addition, population differentiation between islands can provide model systems for studying evolution (Santos et al. 2016). Classic studies of evolutionary biology have focused on the morphology of island birds, such as Darwin's finches (Geospizinae) (Grant \& Grant 2011) and the Hawaiian honeycreepers (Drepanididae) (Pratt 2005). Herrel et al. (2007) suggested that the internal cranial skeleton has crucial importance in both ecological and behavioral contexts. Therefore, we considered

(Received 24 March 2017; Accepted 22 August 2017)

\# Corresponding author, E-mail: mtakagi@eis.hokudai.ac.jp that evaluating the differentiation of skulls between populations of island birds has the potential for providing insights into the ways in which ecological and behavioral factors affect evolution.

The Ryukyu Scops Owl Otus elegans is an island species with a very restricted range of no more than $1,000 \mathrm{~km}$ from north to south. It is mainly distributed throughout the Ryukyu Archipelago of Japan, a small island off southeast Taiwan, and south to small islands north of Luzon, Philippines (Ornithological Society of Japan 2012; Takagi et al. 2015; Gill \& Donsker 2017). Four subspecies are currently recognised: O. e. elegans, O. e. interpositus, O. e. botelensis, and O. e. calayensis (Gill \& Donsker 2017). Two 


\section{A. SAWADA et al.}

subspecies occur in Japan: nominate $O$. e. elegans, which occurs widely on the continental islands of the Ryukyu Archipelago, and the isolated O. e. interpositus, which is endemic to oceanic Minami-daito Island (Fig. 1).

The current subspecific classification is mainly based on plumage characteristics (Kuroda 1923), but more recently, Takagi (2011) revealed that the three populations, those on island groups north and south of the Kerama Gap, and those on Minami-daito Island (Fig. 1) differed in their vocalisations. Features of their morphology seem to be largely attributable to their geohistorical isolation. A recent mitochondrial cytochrome c oxidase subunit I (COI) analysis has supported the subdivision of $O$. e. elegans into northern and southern populations (Saitoh et al. 2015). The genetic independence of the Minami-daito Island $O$. e. interpositus population has also been revealed by a STRUCTURE analysis (Pritchard et al. 2000) of microsatellite regions (Takagi \& Saitoh in preparation). Although their plumage, acoustic, and genetic characteristics have been described in the previous studies mentioned above, their internal morphology has never been described.
We used landmark-based geometric morphometrics to evaluate morphological variation in Computed tomography (CT) scanned skulls of the Ryukyu Scops Owl. CT scanning has become increasingly popular among natural science disciplines as it is entirely non-destructive and provides detailed threedimensional (3D) images of structures (Matthews \& Plessis 2016). The CT images allow us to manipulate, section, dissect and measure internal morphology as well as external morphology (Abel et al. 2012). This characteristic of CT scanning is a necessary property for obtaining internal morphological data of objects that must not be damaged or destroyed, such as precious museum specimens.

Landmark-based geometric morphometrics has been increasingly applied in a range of ornithological studies, such as those on the relationships between ecology and morphology (Kulemeyer et al. 2009; Bright et al. 2016; Matsui et al. 2016) and avian evolution (Bhullar et al. 2012; Bhullar et al. 2015). As traditional morphometrics is based on multivariate analysis of focused variables, such as linear measurements, ratios, angles, areas, and volumes, the results are restricted to those relevant to these

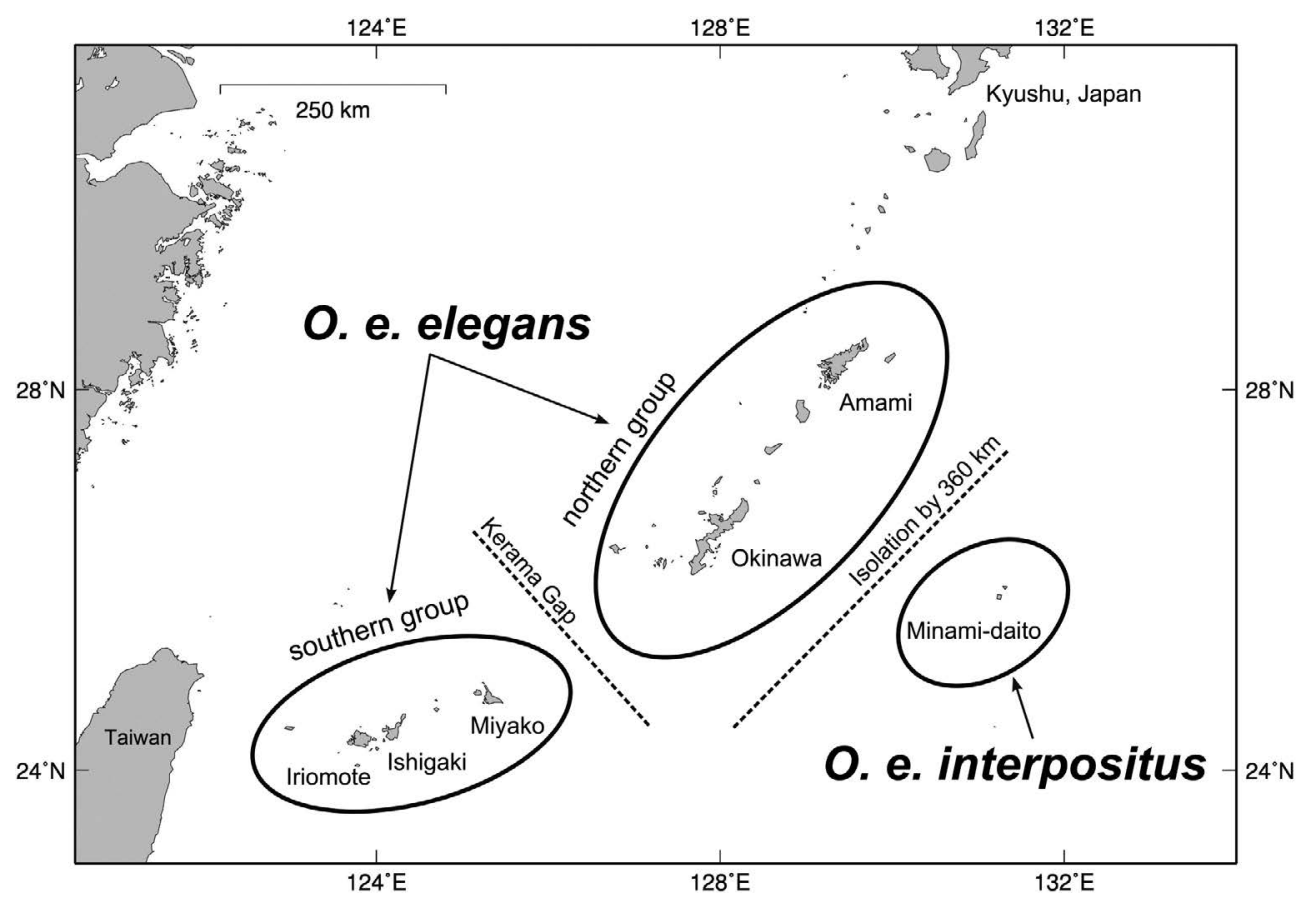

Fig. 1. Three groups of the Ryukyu Scops Owl, the northern and southern groups, and Minami-daito Island, based on genetic analyses (Saitoh et al. 2015; Takagi \& Saitoh in preparation). Ovals show the three groups; the dotted line indicates the Kerama Gap and isolation of Minami-daito Island. The Kerama Gap geographically divides subspecies $O$. e. elegans into northern and southern groups. O. e. interpositus, isolated on Minami-daito Island, is separated by $360 \mathrm{~km}$ from Okinawa, the nearest island. 
a priori selected variables and their combinations (Mitteroecker \& Gunz 2009). However, as landmarkbased geometric morphometrics analyze Cartesian landmark coordinates (Mitteroecker \& Gunz 2009), results can be drawn from any possible relative positioning of the landmarks. Therefore, landmark-based geometric morphometrics is superior to traditional morphometrics, in terms of finding unexpected morphological differences.

In this study, we explored the skull morphology of three different populations of the Ryukyu Scops Owl in order to establish whether any characteristics differ among them, and sought explanations for the differences we found.

\section{MATERIALS AND METHODS}

A total of 28 specimens were derived as follows: six (two males, one female, three of unknown sex) from the Ryukyu Archipelago north of the Kerama Gap; seven (two males, five of unknown sex) from the Ryukyu Archipelago south of the Kerama Gap; and 15 (seven males, four females, four of unknown sex) from Minami-daito Island. Twenty of the specimens were dry museum skins and eight were frozen bodies; 20 were adult, one was a yearling, and seven were of unknown age. All of the specimens of unknown age were sufficiently ossified to allow CT imaging: they were considered to be either yearlings or adults, not juveniles (see Appendix 1).

All 28 skulls were scanned using an X-ray CT system (La Theta LTC-100, Hitachi Aloka Medical, Tokyo, Japan) with slice thickness set to $0.2 \mathrm{~mm}$. Superficial models of the skulls were reconstructed from their CT-data. The digitized 3D-coordinates of the 16 landmarks on the surfaces of model skulls were acquired by means of ImageJ 1.49 (Schneider et al. 2012) (Fig. 2, Table 1). As avian adult neurocranium bones are fused (Zusi 1993), it proved difficult to place landmarks on skulls. Furthermore, some specimens had been damaged around the foramen magnum by taxidermists removing brain tissue from the cranium, making it difficult for us to put landmarks on the skull images. Accordingly, we chose 16 landmarks as a compromise between maximizing the number of landmarks and avoiding missing data,
(R)

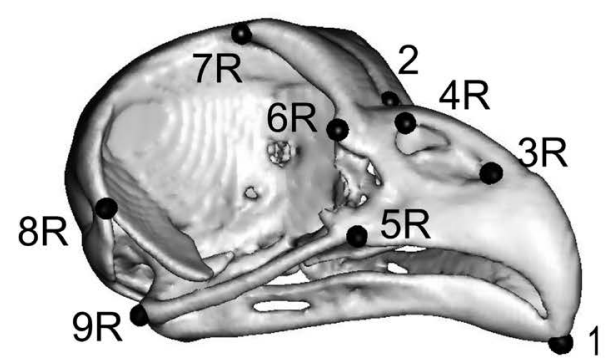

(L)

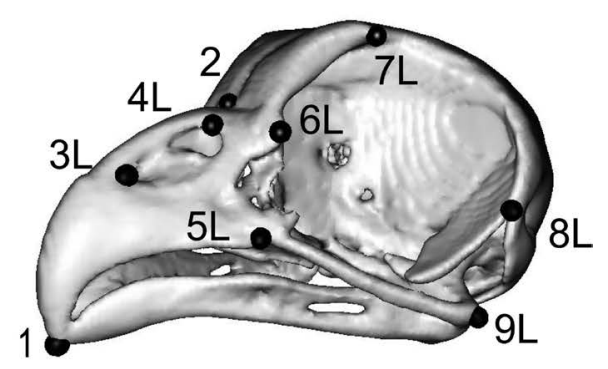

Fig. 2. Landmarks (black dots) on right (R) and left (L) hemispheres of a Ryukyu Scops Owl skull.

Table 1. Landmarks on the skull of the Ryukyu Scops Owl.

\begin{tabular}{ll}
\hline Landmark No. & description \\
\hline 1 & tip of premaxillary \\
2 & midpoint of craniofacial hinge \\
$3 \mathrm{~L} / 3 \mathrm{R}$ & maximum curvature point of anterior end of left/right nares \\
$4 \mathrm{~L} / 4 \mathrm{R}$ & maximum curvature point of posterior end of left/right nares \\
$5 \mathrm{~L} / 5 \mathrm{R}$ & left/right attachment point of jugal and maxillary \\
$6 \mathrm{~L} / 6 \mathrm{R}$ & outermost point of left/right lacrimal \\
$7 \mathrm{~L} / 7 \mathrm{R}$ & tip of left/right dorsal process on orbit \\
$8 \mathrm{~L} / 8 \mathrm{R}$ & diverging point of left/right postorbital process and tympanic wing \\
$9 \mathrm{~L} / 9 \mathrm{R}$ & outermost point of left/right quadrate \\
\hline
\end{tabular}

Description follows nomenclature used in Zusi (1993). Landmark No. corresponds to Fig. 2. 


\section{A. SAWADA et al.}

which emerged in the data of damaged specimens when we put landmarks around the foramen magnum. The geometric features of the skulls were summarized into landmark configurations.

In order to describe the geometric morphometric features of the skulls, first we captured size and shape variation from landmark configurations. Second, we compared skull size and shape between the three groups. Finally, we examined whether the differences found were explained by allometry or not.

Size and shape information were extracted from the original landmark dataset using Generalized Procrustes Analysis (GPA). GPA is based on a leastsquare approach that minimizes the distance between homologous landmarks by translating, scaling, and rotating the original landmark configurations (Slice 2007). The scaling factor extracted through GPA is called "centroid size". The coordinates of the resulting centered, scaled, and rotated landmark configurations are called "Procrustes shape coordinates". Size was represented in centroid size and shape by Procrustes shape coordinates. GPA was conducted using the ProcGPA function, implemented in $\mathrm{R}$ version 3.1.3 (R Core Team 2015) with the package "Morpho" (Schlager 2015).

To evaluate the significance of differences in skull centroid size, we used the Kruskal-Wallis test and the pairwise Wilcoxon rank sum test. Principal component analysis (PCA) summarized variation in Procrustes shape coordinates. First, major principal components (PC), which explained more than $80 \%$ of total variance, were compared by MANOVA to compare PC scores among three groups. Subsequently, the significance of the difference in each PC score was assessed by ANOVA and pairwise $t$ test if MANOVA indicated significance. Holm's correction for P-value adjustment (Holm 1979) was used for all ANOVAs and pairwise comparisons. Before all intergroup comparisons were made, we assessed sexual dimorphism using specimens from Minami-daito Island, as there were multiple samples of both sexes. As no sexual dimorphism either in centroid size or first major PCs of Procrustes shape coordinates was detected (see results), we conducted all analyses on pooled data without separating for sex. We also conducted all analyses without separating for age because all samples including unknown age were deemed to be yearling or adult. Sufficient ossification of yearlings, combined with knowing that the owls first commence breeding when yearlings, support the fact that yearlings have a full grown skeleton and do not differ from adults. We excluded samples of juveniles because they may have different skull structure (Hogg 1980). Visualization of the deformation of skulls along PC axes was obtained from thin plate spline interpolation (Mitteroecker \& Gunz 2009). All statistical analyses were conducted with $\mathrm{R}$ version 3.1.3. Calculation of thin plate spline interpolation was done using the tps $3 d$ function implemented in the R package "Morpho" (Schlager 2015). Deformed skulls were visualized and captured using MeshLab version 1.3.3 (Cignoni et al. 2008).

Explaining shape variation between the three groups by allometry requires one regression line that relates shape to size for the merged group. For the purpose of drawing this regression line, we adopted a procedure consisting of two steps. The first step involved fitting a regression line for each of the three groups. Depending on the results of the first step, we followed one of the following three sub-procedures in the second step: a) If no significant regression line was detected in any of the three groups, or detected for only one group, we conducted a regression analysis using merged data; b) If significant regression lines were obtained for at least two of the groups and these lines did not differ statistically from each other, we also conducted merged data analysis; c) If regression lines for at least two of the groups proved to be significantly different, pooled analysis was not justifiable, and not conducted.

We conducted Procrustes ANOVA (Goodall 1991) using the procD.lm function of $\mathrm{R}$ package "geomorph" (Adams \& Otárola-Castillo 2013) in order to test the significance of regressions with a permutation test in the first step. In cases when significant regression lines were detected (i.e., cases (b) or (c) above), we aimed to test the homogeneity of slopes and intercepts using the advanced.procD.lm function of R package "geomorph". To summarize variation in the Procrustes shape coordinates, which was not explained by the size factor, we performed PCA on the residual of the regression analysis of merged data. We used the same statistical procedures for analysing residual Procrustes shape coordinates as described above.

\section{RESULTS}

\section{Size difference}

Centroid size did not differ significantly between males and females (Wilcoxon rank sum test, $\mathrm{n} 1=7$, $\mathrm{n} 2=4, \mathrm{~W}=19, \mathrm{NS})$, but differed significantly between 
the three population groups (Kruskal-Wallis test, chi-squared $=10.58, \mathrm{df}=2, \mathrm{P}<0.01)$. Pairwise Wilcoxon rank sum tests revealed that the centroid size of $O$. e. interpositus was significantly smaller than

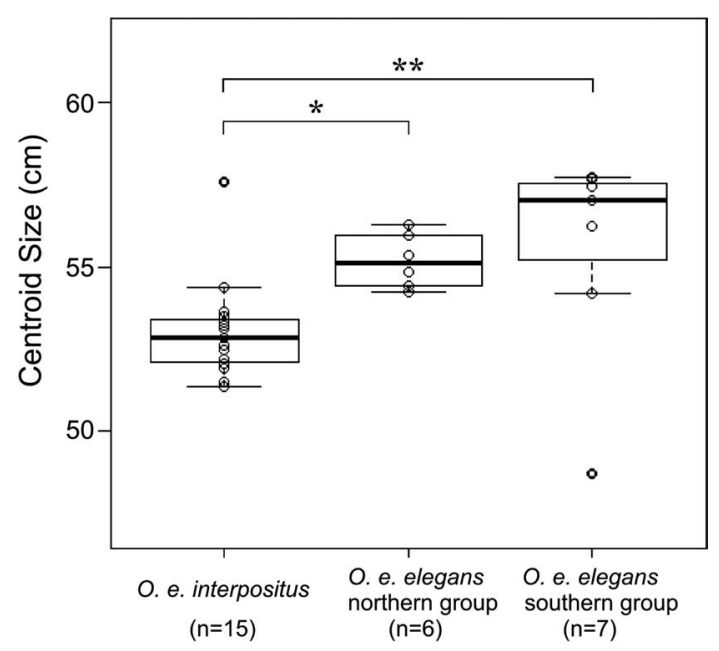

Fig. 3. Comparison of centroid size between three groups of Ryukyu Scops Owls. ${ }^{*} \mathrm{P}<0.05,{ }^{*} \mathrm{P}<0.01$ that of the northern $(\mathrm{n} 1=15, \mathrm{n} 2=6, \mathrm{~W}=83$, adjusted $\mathrm{P}<0.05$, Fig. 3) and that of the southern ( $1=15$, $\mathrm{n} 2=7, \mathrm{~W}=85$, adjusted $\mathrm{P}<0.05$, Fig. 3) groups of O. e. elegans. However, differences between the two groups of $O$. e. elegans $(\mathrm{n} 1=6, \mathrm{n} 2=7, \mathrm{~W}=29, \mathrm{NS}$, Fig. 3) were not significant.

\section{Shape difference}

The first eight PCs in the original Procrustes shape coordinates explained $81.3 \%$ of the total shape variation (see Appendix 2 for detailed data). These PC scores did not differ significantly between males and females (MANOVA, $\mathrm{df}=8,2, \mathrm{~F}=2.85$, Pillai Trace $=0.92$, NS), but did differ significantly between the three regional groups (MANOVA, $\mathrm{df}=16,38$, $\mathrm{F}=2.96$, Pillai Trace $=1.11, \mathrm{P}<0.01)$. $\mathrm{PC} 1$, which explained $22.9 \%$ of total shape variation, showed a significant difference among the three groups (ANOVA, df $=2,25, \mathrm{~F}=39.32, \mathrm{P}<0.01$, Appendix 2, Fig. 4). With the exception of PC1, none of the other major PCs differed significantly between the

\section{Deformation along PC1}

Comparison of PC1 Scores

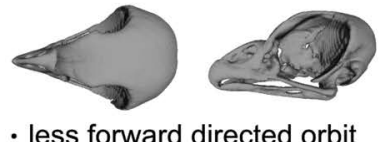

- less forward directed orbit - anteroposteriory long skull

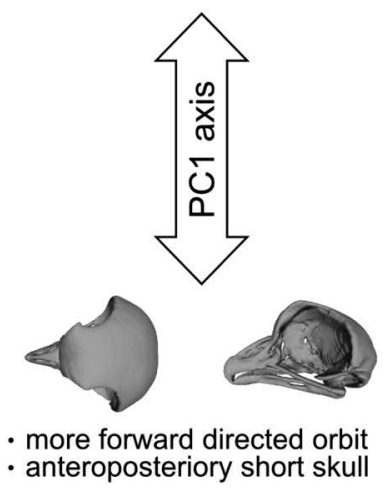

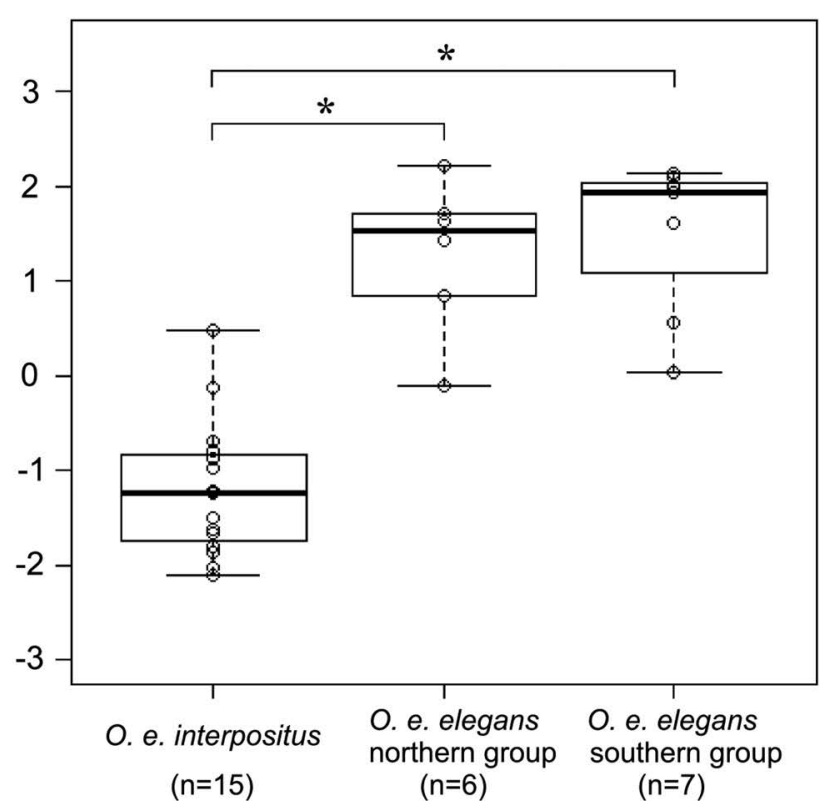

$(n=15)$ $(n=6)$

$(n=7)$

Fig. 4. Comparison of PC1 score of original Procrustes shape coordinates and deformation of the skull along the PC1 axis in the Ryukyu Scops Owl. ${ }^{*} \mathrm{P}<0.001$. Landmarks on average shaped skulls were moved along the PC1 axis so that the resultant landmark configuration has a mean +4SD PC1 score (upper row) or mean -4SD PC1 score (lower row). Each skull is expressed as a vector whose components are coordinates of landmarks on the skull. PC score consists of a linear combination of coordinates of landmarks. Therefore, moving landmarks on a skull, i.e. adding a vector to the vector of coordinates of landmarks, causes changes in PC scores of the skull. Actually, adding a scaled eigenvector of PCA can increase or decrease the corresponding PC score. Extent of the change depends on the scaling factor (see Appendix of Mitteroecker et al. 2013). The remaining surface of an average shaped skull was deformed by thin plate spline interpolation in accordance with the changes in the landmark positions. Deformed skulls are shown from lateral (right) and dorsal views (left). 


\section{A. SAWADA et al.}

three groups (see Appendix 2 for detailed results of ANOVA). Further analysis was conducted only for $\mathrm{PC} 1$. The $\mathrm{PC} 1$ score of $O$. e. interpositus was significantly smaller than those of the northern (t-test, $\mathrm{df}=8.36, \mathrm{t}=6.51, \mathrm{P}<0.001)$ and the southern groups (t-test, $\mathrm{df}=10.37, \mathrm{t}=7.28, \mathrm{P}<0.001)$. The northern and southern groups of $O$. e. elegans did not differ from each other ( $\mathrm{t}$-test, $\mathrm{df}=10.79, \mathrm{t}=0.43, \mathrm{NS}$ ). Deformation of the average-shaped skull along the PC1 axis showed that PC1 mainly represented relative anteroposterior length and the angle of the orbit (Fig. 4). In other words, birds belonging to $O$. $e$. interpositus have relatively short skulls with orbits positioned further forward than in other populations.

\begin{abstract}
Allometry
We did not detect any significant regression lines for the three groups by multivariate regression analysis of Procrustes shape coordinates on log centroid size (permutation test; 10,000 permutations, NS for all groups). We obtained a significant regression line when analyzing the merged data (permutation test; 10,000 permutations, $\mathrm{P}<0.001$ ). The first eight $\mathrm{PCs}$ from the PCA based on residual Procrustes shape coordinates explained $80.5 \%$ of the total shape variation (see Appendix 3 for detailed data). As none of these PC scores differed significantly between the three groups (MANOVA, $\mathrm{df}=16,38, \mathrm{~F}=1.80$, Pillai Trace $=0.86$, NS), we did not perform any subsequent ANOVAs for each PC.
\end{abstract}

\section{DISCUSSION}

The objective of this research was to study, detect and evaluate any differences between the skulls of three geographically separated populations of the Ryukyu Scops Owl, to infer causal factors for any differences, and to propose explanations for how differences might have evolved. Analyses revealed differences both in size and shape between $O$. e. interpositus and $O$. e. elegans. Multivariate regression of Procrustes shape coordinates on the logarithm of centroid size for each group did not indicate significant allometric relationships. However, regression analysis of a merged group provided significance. Analyses based on residual Procrustes shape coordinates did not indicate subspecific shape differences.

Pairwise comparisons revealed that centroid size differed between O. e. interpositus and O. e. elegans. We inferred that small skull size on the small (ca. 30 $\mathrm{km}^{2}$ ), isolated, oceanic Minami-daito Island might be partly attributable to founder effects. A STRUCTURE analysis of microsatellite regions (Takagi \& Saitoh in preparation) suggests that the population on Minami-daito Island was founded by individuals from the population on Okinawa Island, which is included within the northern group of $O$. e. elegans. Our results showed that some individual $O$. e. elegans had skulls as small as those of $O$. e. interpositus (Fig. 3), and we propose that founders reaching Minami-daito Island may have had such characteristics. Conversely, however, other evolutionary selection processes may have favored small skull size on Minami-daito Island after initial arrival. Clegg and Owens (2002) discussed how the effects of changes in feeding ecology, intraspecific competition, energetic constraints and physiological optimization in birds on small islets seem to have an important role in size evolution. However, as yet we do not have data supporting or confirming either perspective.

Principle component analysis revealed that cranial shape also differed substantially between $O$. e. interpositus and $O$. e. elegans, for which there seem to be three possible explanations. The first possibility is allometry, one of the factors causing morphological variation among organisms that differ in body size (Mitteroecker et al. 2013). The results of the PCA of residual Procrustes shape coordinates suggest the possibility that variation between subspecies can be simply explained as an allometric effect of skull size. The disappearanc of significance of $\mathrm{PC} 1$, after controlling for size, suggest that the PC1 of original Procrustes shape coordinates mainly represents allometric variation in the data. Actually, allometry is the most dominant factor of shape and form variation (Mitteroecker et al. 2013). However, explanation by allometry requires careful interpretation of results, because multivariate regressions in each group did not indicate significant allometric relationships. If each group actually has a different regression line, then multivariate regression analysis for merged data is not justified and we need a different explanation, such as that offered below.

The second possibility is that adaptation to foraging behaviour using binocular vision has occurred. Orientation of the orbits may be related to variation in the visual field (Heesy 2004; Fernández-Juricic et al. 2008), which may reveal a trade-off relationship between foraging and predator detection (Martin 2014). Hunting owls swing their feet up into the area of binocular vision just prior to prey capture (Martin 2007). Although forward positioned eyes 
increase accuracy during this prey capturing behavior, such positioning decreases lateral vision rendering the hunting owl more susceptible to predators attacking from the side. Potential nocturnal predators, such as Protobothrops snakes, do not occur on oceanic Minami-daito Island, whereas they do occur on almost all of the other continental islands in the Ryukyu Archipelago. Adaptations among the owls on Minami-daito Island might have led to them having eyes positioned further forward thus increasing their hunting accuracy. To verify this trade-off relationship, future studies should include analysis of morphometric data in relation to the presence or absence of predators on each island. Quantitative evaluation of visual fields is also desirable (i.e., Fernández-Juricic et al. 2008; Martin \& Piersma 2009).

The third explanation for the difference in skull shape is morphological integration. Each part of the skull is integrated with other parts because they develop, function, and evolve together (Klingenberg 2013). The observed shape difference may result from such covariation of skull parts. In other words, part of the observed variation may be caused by variation in other parts, i.e. variation that is explained by other factors such as adaptation. In this study, we were compelled to adopt a small number of landmarks due to the limitation of the material properties of the specimens (as described above). To accurately evaluate shape covariation among parts, many more landmarks including semi-landmarks are needed (Kulemeyer et al. 2009; Gunz \& Mitteroecker 2013).

Our study has shown that two subspecies of Ryukyu Scops Owl exhibit substantially different skull size and shape. Such differences may be explained by allometry, adaptation, or morphological integration. However, the variation detected should be interpreted carefully. Our results are based on a relatively small sample size including individuals of unknown sex. A larger sample with sexed specimens would help to improve our understanding of their morphological evolution.

\section{ACKNOWLEDGMENTS}

We thank Isao Nishiumi for providing specimens. We also thank Masaaki Eda, and anonymous referees for providing insightful comments on the manuscript. We would also like to thank Mark Brazil, Scientific Editing Services, for assistance in the preparation of the final draft of the manuscript. Takeshi Yamasaki received funds from JSPS Kakenhi (Grant Num- bers JP24120002 and JP24120007). Masaoki Takagi received a fund from JSPS Kakenhi (Grant Number 16H04737).

\section{REFERENCES}

Abel RL, Laurini CR \& Richter M (2012) A palaeobiologist's guide to 'virtual' micro-CT preparation. Palaeontol Electronica 15: 6T.

Adams DC \& Otárola-Castillo E (2013) geomorph: an $\mathrm{R}$ package for the collection and analysis of geometric morphometric shape data. Methods Ecol Evol 4: 393-399.

Bhullar BAS, Marugán-Lobón J, Racimo F, Bever GS, Rowe TB \& Norell MA et al. (2012) Birds have paedomorphic dinosaur skulls. Nature 487: 223-226.

Bhullar BAS, Morris ZS, Sefton EM, Tok A, Tokita M \& Namkoong B et al. (2015) A molecular mechanism for the origin of a key evolutionary innovation, the bird beak and palate, revealed by an integrative approach to major transitions in vertebrate history. Evolution 69: 1665-1677.

Bright JA, Marugán-lobón J, Cobb SN \& Rayfield EJ (2016) The shapes of bird beaks are highly controlled by nondietary factors. Proc Natl Acad Sci USA 113: 5352-5357.

Cignoni P, Corsini M \& Ranzuglia G (2008) MeshLab: an open-source 3D mesh processing system. ERCIM News 73: 45-46.

Clegg SM \& Owens PF (2002) The "island rule" in birds: medium body size and its ecological explanation. P Roy Soc B-Biol Sci 269: 1359-1365.

Fernández-Juricic E, Gall MD, Dolan T, Tisdale V \& Martin GR (2008) The visual fields of two groundforaging birds, House Finches and House Sparrows, allow for simultaneous foraging and anti-predator vigilance. Ibis 150: 779-787.

Gill F \& Donsker D (2017) IOC world bird list (v 7.2). Available at http://www.worldbirdnames.org/ (accessed on 16 May 2017).

Goodall C (1991) Procrustes methods in the statistical analysis of shape. J Roy Stat Soc B 53: 285-339.

Grant PR \& Grant BR (2011) How and why species multiply: the radiation of Darwin's finches. Princeton University Press, Princeton.

Gunz P \& Mitteroecker P (2013) Semilandmarks: a method for quantifying curves and surfaces, point homology, placing semilandmarks. Hystrix 24: $103-$ 109.

Heesy CP (2004) On the relationship between orbit orientation and binocular visual field overlap in mammals. Anat Rec Part A 281: 1104-1110.

Herrel A, Schaerlaeken V, Meyers JJ, Metzger KA \& 


\section{A. SAWADA et al.}

Ross CF (2007) The evolution of cranial design and performance in squamates: consequences of skullbone reduction on feeding behavior. Integr Comp Biol 47: 107-117.

Hogg DA (1980) A re-investigation of the centres of ossification in the avian skeleton at and after hatching. J Anat 130: 725-743.

Holm S (1979) A simple sequentially rejective multiple test procedure. Scand J Stat 6: 65-70.

Klingenberg CP (2013) Cranial integration and modularity: insights into evolution and development from morphometric data. Hystrix 24: 43-58.

Kulemeyer C, Asbahr K, Gunz P, Frahnert S \& Bairlein $F$ (2009) Functional morphology and integration of corvid skulls - a 3D geometric morphometric approach. Front Zool 6: 2.

Kuroda N (1923) Descriptions of apparently new forms of birds from the Borodino Islands, Ryukyu group, Japan. Bull Brit Ornithol Club 43: 120-123.

Martin GR (2007) Visual fields and their functions in birds. J Ornithol 148 (Suppl 2): 547-562.

Martin GR (2014) The subtlety of simple eyes: the tuning of visual fields to perceptual challenges in birds. Philos T Roy Soc B 369: 20130040.

Martin GR \& Piersma T (2009) Vision and touch in relation to foraging and predator detection: insightful contrasts between a plover and a sandpiper. P Roy Soc Lond B Bio 276: 437-445.

Matsui H, Hunt GR, Oberhofer K, Ogihara N, McGowan KJ \& Mithraratne K et al. (2016) Adaptive bill morphology for enhanced tool manipulation in New Caledonian crows. Sci Rep-UK 6: 22776.

Matthews T \& du Plessis A (2016) Using X-ray computed tomography analysis tools to compare the skeletal element morphology of fossil and modern frog (Anura) species. Palaeontol Electronica 19: 1T.

Mitteroecker P \& Gunz P (2009) Advances in geometric morphometrics. Evol Biol 36: 235-247.

Mitteroecker P, Gunz P, Windhager S \& Schaefer K (2013) A brief review of shape, form, and allometry in geometric morphometrics, with applications to human facial morphology. Hystrix 24: 59-66.

Ornithological Society of Japan (2012) Check-list of Japanese birds. 7th ed. The Ornithological Society of Japan, Sanda.

Pratt HD (2005) The Hawaiian honeycreepers: Drepanididae. Oxford University Press, Oxford.

Pritchard JK, Stephens M \& Donnelly P (2000) Inference of population structure using multilocus genotype data. Genetics 155: 945-959.

R Core Team (2015) R: a language and environment for statistical computing. $\mathrm{R}$ foundation for statistical computing, Vienna, Austria. Available at http:// www.R-project.org/ (accessed on 16 May 2017).

Saitoh T, Sugita N, Someya S, Iwami Y, Kobayashi S \& Kamigaichi $\mathrm{H}$ et al. (2015) DNA barcoding reveals 24 distinct lineages as cryptic bird species candidates in and around the Japanese Archipelago. Mol Ecol Resour 15: 177-186.

Santos AMC, Field R \& Ricklefs RE (2016) New directions in island biogeography. Global Ecol Biogeogr 25: $751-768$.

Schlager S (2015) Morpho: calculations and visualisations related to geometric morphometrics. R package version 2.3.1. Available at http://cran.r-project.org/ package $=$ Morpho (accessed on 16 May 2017).

Schneider CA, Rasband WS \& Eliceiri KW (2012) NIH Image to ImageJ: 25 years of image analysis. Nat Methods 9: 671-675.

Slice DE (2007) Geometric Morphometrics. Annu Rev Anthropol 36: 261-281.

Takagi M (2011) Vicariance and dispersal in the differentiation of vocalization in the Ryukyu Scops Owl Otus elegans. Ibis 153: 779-788.

Takagi M, Saitoh T, Yamaguchi N, Okabe H, Nishiumi I \& Takeishi M (2015) A breeding record of the Ryukyu Scops Owl on Okinoshima, in northernmost Fukuoka, Japan. Ornithol Sci 14: 53-59.

Zusi RL (1993) Patterns of diversity in the avian skull. In: Hanken J \& Hall BK (eds) The skull, Volume 2: patterns of structural and systematic diversity. pp. 391-437. University of Chicago Press, Chicago. 
Skull features in the Ryukyu Scops Owl

Appendix 1. Ryukyu Scops Owl specimens examined in this study.

\begin{tabular}{|c|c|c|c|c|c|c|c|}
\hline Specimen No. & Owner & Island & Subspecies & Group & Sex & Stage & State \\
\hline YIO-19205 & YIO & Minami-daito & interpositus & & Female & Unknown & Museum skin \\
\hline YIO-19207 & $\mathrm{YIO}$ & Minami-daito & interpositus & & Male & Unknown & Museum skin \\
\hline YIO-19208 & YIO & Minami-daito & interpositus & & Female & Unknown & Museum skin \\
\hline YIO-19210 & YIO & Minami-daito & interpositus & & Male & Unknown & Museum skin \\
\hline YIO-19216 & YIO & Okinawa & elegans & northern & Male & Adult & Museum skin \\
\hline YIO-19229 & YIO & Iriomote & elegans & southern & Unknown & Adult & Museum skin \\
\hline YIO-62371 & YIO & Ishigaki & elegans & southern & Unknown & Unknown & Museum skin \\
\hline YIO-64984 & YIO & Iriomote & elegans & southern & Unknown & Adult & Museum skin \\
\hline 2004-0129 & YIO & Iriomote & elegans & southern & Unknown & Unknown & Frozen body \\
\hline $2015-1084$ & YIO & Minami-daito & interpositus & & Female & Adult & Museum skin \\
\hline $2015-1086$ & YIO & Minami-daito & interpositus & & Male & Adult & Museum skin \\
\hline $2015-1087$ & YIO & Minami-daito & interpositus & & Unknown & Adult & Frozen body \\
\hline 2015-1089 & YIO & Minami-daito & interpositus & & Unknown & Adult & Frozen body \\
\hline 2015-1092 & YIO & Minami-daito & interpositus & & Unknown & Adult & Frozen body \\
\hline $2015-1093$ & YIO & Minami-daito & interpositus & & Female & Yearling & Museum skin \\
\hline 2015-1094 & YIO & Minami-daito & interpositus & & Male & Adult & Frozen body \\
\hline $2015-1104$ & YIO & Minami-daito & interpositus & & Unknown & Adult & Frozen body \\
\hline $2015-1105$ & YIO & Minami-daito & interpositus & & Male & Adult & Museum skin \\
\hline 2015-1106 & YIO & Minami-daito & interpositus & & Male & Adult & Frozen body \\
\hline $2015-1110$ & YIO & Minami-daito & interpositus & & Male & Adult & Frozen body \\
\hline NSMTA-13193 & NMNS & Iriomote & elegans & southern & Unknown & Unknown & Museum skin \\
\hline NSMTA-17395 & NMNS & Okinawa & elegans & northern & Male & Adult & Museum skin \\
\hline NSMTA-17402 & NMNS & Okinawa & elegans & northern & Female & Adult & Museum skin \\
\hline NSMTA-17501 & NMNS & Amami & elegans & northern & Unknown & Adult & Museum skin \\
\hline NSMTA-17504 & NMNS & Amami & elegans & northern & Unknown & Adult & Museum skin \\
\hline NSMTA-17511 & NMNS & Amami & elegans & northern & Unknown & Adult & Museum skin \\
\hline NSMTA-17615 & NMNS & Iriomote & elegans & southern & Male & Adult & Museum skin \\
\hline NSMTA-17616 & NMNS & Iriomote & elegans & southern & Male & Adult & Museum skin \\
\hline
\end{tabular}

Abbreviations: YIO, Yamashina Institute for Ornithology; NMNS, National Museum of Nature and Science.

Appendix 2. Results of the principal component analysis (PCA) on original Procrustes shape coordinates and the analysis of variance (ANOVA).

\begin{tabular}{cccccc}
\hline \multirow{2}{*}{$\begin{array}{c}\text { Principle } \\
\text { component }\end{array}$} & $\begin{array}{c}\text { Explained } \\
\text { variance }(\%)\end{array}$ & $\begin{array}{c}\text { Cumulative } \\
\text { explained } \\
\text { variance }(\%)\end{array}$ & \multicolumn{3}{c}{ ANOVA } \\
\cline { 4 - 6 } PC1 & 22.9 & 22.9 & 39.32 & 0.000 & $*$ \\
PC2 & 16.6 & 39.5 & 0.01 & 0.995 & \\
PC3 & 13.8 & 53.3 & 0.46 & 0.637 & \\
PC4 & 8 & 61.3 & 3.31 & 0.053 & \\
PC5 & 7 & 68.3 & 0.51 & 0.608 & \\
PC6 & 5.4 & 73.7 & 0.06 & 0.947 & \\
PC7 & 4.3 & 78.1 & 0.18 & 0.838 & \\
PC8 & 3.2 & 81.3 & 0.64 & 0.536 & \\
\hline
\end{tabular}

Significance: * $\mathrm{P}<0.01$ after Holm's P-value correction 


\section{A. SAWADA et al.}

Appendix 3. Results of the principal component analysis (PCA) on residual Procrustes shape coordinates and the analysis of variance (ANOVA).

\begin{tabular}{|c|c|c|c|c|c|}
\hline \multirow{2}{*}{$\begin{array}{l}\text { Principle } \\
\text { component }\end{array}$} & \multirow{2}{*}{$\begin{array}{c}\text { Explained } \\
\text { variance }(\%)\end{array}$} & \multirow{2}{*}{$\begin{array}{c}\text { Cumulative } \\
\text { explained } \\
\text { variance }(\%)\end{array}$} & \multicolumn{3}{|c|}{ ANOVA } \\
\hline & & & $\mathrm{F}(2,25)$ & $\mathrm{P}$ & Significance \\
\hline $\mathrm{PC} 1$ & 19.8 & 19.8 & 2.98 & 0.069 & \\
\hline $\mathrm{PC} 2$ & 15.8 & 35.6 & 2.43 & 0.108 & \\
\hline PC3 & 14.1 & 49.7 & 2.53 & 0.100 & \\
\hline PC4 & 8.9 & 58.6 & 3.44 & 0.048 & \\
\hline PC5 & 7.9 & 66.5 & 0.51 & 0.606 & \\
\hline PC6 & 5.6 & 72.1 & 0.22 & 0.807 & \\
\hline $\mathrm{PC} 7$ & 4.8 & 76.9 & 0.23 & 0.797 & \\
\hline PC8 & 3.6 & 80.5 & 0.68 & 0.519 & \\
\hline
\end{tabular}

Significance: * $\mathrm{P}<0.01$ after Holm's P-value correction 